\title{
La nueva utilidad de la prostitución en el neoliberalismo
}

\section{The new utility of prostitution in neoliberalism}

Beatriz Gimeno

Recibido: 02/10/2017

Aceptado: 15/01/2018

\section{RESUMEN}

En este artículo se pretende explicar la transformación sufrida por la institución de la prostitución desde que en los años 70 y 80 se convierte en una de las industrias transnacionales más importantes del mundo. En esos años, al mismo tiempo que se convierte en una megaindustria sufre también una transformación en cuanto a su funcionalidad como institución patriarcal. Progresivamente está dejando de ser exclusivamente una manera de dividir a las mujeres en esposas/putas así como de justificar una determinada ideología sexual, y se está convirtiendo también en una manera de reasegurar las masculinidades más tradicionales, acosadas por los éxitos del feminismo. Al mismo tiempo también se está convirtiendo en el necesario alivio social para una población masculina a la que un neoliberalismo brutal ha situado en una situación en la que antes sólo se encontraban las mujeres.

Palabras clave: prostitución, neoliberalismo, masculinidad hegemónica

\section{ABSTRACT}

This article aims to explain the transformation of the industry of prostitution since the 70s and 80s, when it became one of the most important transnational industries in the world. In those years, just at the same time it becomes a megaindustry, it also undergoes a transformation in terms of its functionality as a patriarchal institution. It is gradually ceasing to be exclusively a way to divide women into wives and whores and also a way to justify a certain sexual ideology, in order to become a way of reassuring the more traditional masculinities, beset by the successes of feminism. At the same time, it is also becoming the necessary social relief for a male population placed, under a brutal neoliberalism wave, in a situation in which only women previously where.

Keywords: prostitution, neoliberalism, hegemonic masculinity

Beatriz Gimeno es activista feminista y escritora. Entre sus últimas publicaciones destacan "Lactancia materna, política e identidad" (2018) y "La prostitución: aportaciones para un debate abierto" (2012). Correo electrónico: gimeno.beatriz@gmail.com.

Cómo citar este artículo: Gimeno, B. (2018). La nueva utilidad de la prostitución en el neoliberalismo. Atlánticas. Revista Internacional de Estudios Feministas, 3 (1), 13-32 doi: http:/ /dx.doi.org/10.17979/arief.2018.3.1.3077 


\section{INTRODUCCIÓN}

El patriarcado es un sistema que -entre otras cosas- trata de ordenar (y garantizar) el acceso al cuerpo masculino de las mujeres y así asegurarse la apropiación de la descendencia. Como afirma Amorós (2005:127) el patriarcado no es estable, sino que es un conjunto práctico, es decir, que se constituye en y mediante un sistema de prácticas reales y simbólicas y toma su consistencia de estas prácticas, instituciones, dispositivos... que pueden ir variando adaptativamente. La prostitución es una de las instituciones o dispositivos estructurantes del patriarcado junto a otras como -inicialmente- el matrimonio. Ambas han sido, durante gran parte de la historia, las dos caras de la misma moneda y por eso ambas han sido objeto de atención y crítica por parte del feminismo. No vamos a entrar en la segunda, que no es el objeto de este artículo, pero el cambio que ha sufrido en el último siglo, al menos en los países democráticos, ha sido inmenso, ha perdido su funcionalidad patriarcal en gran parte y ya no sirve para aquello que fue creado. Por el contrario, la prostitución no sólo conserva dicha funcionalidad, sino que la ha renovado con nuevos significados, que permiten que siga siendo útil e, incluso, imprescindible. Eso no quiere decir que no haya cambiado. Lo ha hecho, y mucho. Partiendo de que la prostitución es una institución patriarcal que tiene como objetivo principal ordenar y/o mantener la desigualdad sexual, hay que tener en cuenta que ésta se organiza de manera diferente según las distintas culturas en las que se presente y también según el distinto tiempo histórico. La desigualdad sexual, el orden de género en palabras de Connell, no requiere siempre de los mismos instrumentos de control, de vigilancia o, incluso, de refuerzo. El patriarcado muta constantemente, sus herramientas también. No es lo mismo un patriarcado fuerte, indiscutible, que sólo requiere de instituciones de normalización o de ordenación del mismo, que un patriarcado fragilizado, puesto en cuestión y combatido desde todos los ángulos y que requiere de refuerzo continuo. Por ponerlo en palabras de Alicia Puleo (1995) ${ }^{1}$, un patriarcado de coerción que uno de consentimiento (basado en el contrato).

A comienzos del siglo XX la mayoría de los sociólogos, historiadores o sexólogos habían llegado a la conclusión de que en el momento en que las mujeres pudieran acceder mayoritariamente al trabajo remunerado y también a

\footnotetext{
${ }^{1}$ Alicia H. Puleo distingue entre dos tipos de patriarcado: patriarcados de coerción: los que estipulan por medio de leyes o normas consuetudinarias sancionadoras con la violencia aquella que está permitido y prohibido a las mujeres y los patriarcados de consentimiento, aquellos donde sí hay igualdad formal ante la ley y que serían los occidentales contemporáneos que incitan los roles sexuales a través de imágenes atractivas y poderosos mitos vehiculizados en gran parte por los medios de comunicación.
} 
una vida sexual autónoma sin ser condenadas por ello, el uso prostitucional de las mujeres por parte de los hombres tendría que desaparecer, o disminuir al menos (Gimeno 2012). Puesto que ahora las mujeres también querían sexo, y este deseo ya no era un motivo de estigmatización; si no tenían miedo tampoco al embarazo y tampoco era casarse su principal preocupación, entonces la prostitución ya no sería útil. La igualdad, que avanzaba a buen paso, tenía que llegar también al campo de la sexualidad. Y es cierto que en las décadas de los 50 y 60 se produjo un apreciable descenso en el uso de la prostitución, disminución que se atribuyó a la llamada revolución sexual. Kinsey, por ejemplo, recoge en su informe un importante declive de la prostitución (1948: 596-609), lo que le hace aventurar que ésta está condenada a ir desapareciendo hasta convertirse en residual. Pero, sorpresivamente, ocurrió lo contrario. Desde los años 70 y en los 80 especialmente, lo que se produjo fue un espectacular aumento que ha superado todas las expectativas hasta el punto de que hoy día hay países enteros cuyo PIB depende de la industria del sexo en cualquiera de sus manifestaciones. ¿Por qué en lugar de disminuir el uso de la prostitución no ha hecho sino aumentar desde los años 70 hasta convertirse en lo que es hoy?

Las razones son varias e interrelacionan entre sí de maneras complejas. Pero me quiero referir aquí a dos cuestiones fundamentales que están relacionadas con cambios sufridos en la organización patriarcal, que a su vez están relacionados con esta fase del capitalismo tardío que conocemos por neoliberalismo. De manera simplificada: la prostitución ha cambiado en los últimos años en dos sentidos fundamentales: ha pasado de ser una actividad individual a ser una actividad empresarial (cambio relacionado a su vez con una profunda transformación en la consideración social del sexo) $\mathrm{Y}$ en segundo lugar ha pasado de configurar absolutamente la identidad femenina (la identidad de puta) a configurar identidades masculinas tradicionales.

\subsection{De práctica individual a mercado global}

La prostitución es una institución que tiene un significado social que va más allá de las prácticas personales de quienes la ejercen o la usan; se hace inteligible y es socialmente apoyada en tanto que se basa, visibiliza y refuerza una determinada construcción ideológica de la sexualidad que la mayoría de la gente comparte. Una construcción patriarcal que la convierte en una herramienta básica de la desigualdad sexual. Esa ideología sexual afirma, de 
manera simplificada que los hombres tienen necesidades sexuales irreprimibles que deben consumar o de lo contrario se producirán grandes males. La justificación tradicional de la prostitución ha sido siempre esta. Así la han justificado las religiones, los filósofos, los científicos sociales e incluso los revolucionarios. ¿Cómo hacer compatible la obligada fidelidad de las mujeres a un hombre -lo único que garantiza la paternidad cierta- con la ilimitada promiscuidad masculina, y hacerlo sin generar constantes conflictos con los dueños de esas mujeres? Pues la única manera es crear un contingente de mujeres públicas al servicio de esa sexualidad masculina irreprimible, torrencial. Además, la prostitución es útil para dividir a las mujeres en buenas y malas, santas y putas y así, mediante el uso del estigma, el patriarcado se asegura de que las buenas no deseen compartir el destino de las putas (Gimeno 2012: 185 y ss.) En los antiguos patriarcados de coerción la prostitución era una institución entre otras que servía más para regular un acceso ordenado a las mujeres que para reafirmar el poder masculino ya que en realidad, éste se encontraba confirmado por todo, por todas las prácticas, por todas las instituciones sociales, legales y simbólicas. El poder masculino no necesitaba de especiales refuerzos puesto que todo lo confirmaba.

Pero ese panorama social se ha visto convulsionado desde la mitad del siglo pasado, cuando el empuje del feminismo no solo ha logrado la igualdad formal, sino que ha presionado sobre el orden de género en todos los aspectos posibles: legales, culturales, simbólicos, subjetivos. El feminismo ha zarandeado el orden de género y, ya lo sabemos, cuando el género se mueve, todo se mueve. Las mujeres han irrumpido en el espacio de la ciudadanía política por primera vez y desde ahí presionan para ensanchar ese espacio y derruir el andamiaje de la desigualdad sexual. Y dentro de los cambios la sexualidad ha sido uno de los espacios que ha sufrido una mayor transformación. Aparece el feminismo para reivindicar para las mujeres la categoría de sujeto sexual, para reivindicar el deseo y el placer. Esto hizo que el estigma sobre las mujeres sexuales se fuera debilitando. A esto contribuyó la aparición de la píldora y los anticonceptivos seguros. Se hicieron cotidianos, además, los espacios de socialización mixtos y, por último, las mujeres accedieron al trabajo remunerado y ya no se veían en la necesidad de intercambiar sexo e hijos a cambio de ser mantenidas. El resultado de todo esto unido vino a transformar completamente los usos sexuales desde la mitad del siglo XX. Uno de los cambios fundamentales es que, poco a poco, el sexo no sólo se banaliza, sino que se convierte en un espacio de legitimación, en 
un artículo de consumo, en una mercancía más, una de los más importantes del mercado mundial.

Cuando el sexo se convierte en una mercancía ${ }^{2}$ la prostitución deja de ser una práctica individual con la que algunas mujeres se ganaban la vida para convertirse en una poderosa industria que tiene a las mujeres como materia prima. Esa industria ya no necesita de ninguna ideología para justificar su existencia, esas supuestas necesidades masculinas. Su justificación ahora no es otra que la de cualquier artículo de consumo: el supremo derecho a consumir cualquier cosa por la que se pueda pagar. El sexo es una mercancía más pero, además, una de las más vendibles. "El sexo es vida" afirma una conocida campaña publicitaria. El sexo es vida, felicidad, éxito, juventud. No tener sexo es tristeza, fracaso, aburrimiento, muerte. No hay un producto de consumo más exitoso que el sexo. Ahora, la prostitución se presenta como una práctica banal ligada al consumo, al ocio, a la moda, a la diversión y a la libertad individual tal como la entiende el neoliberalismo, libertad para comprar y vender sin importar las condiciones estructurales de partida, ni los significados estructurantes de la opresión o la dominación, todo análisis político y/o de género desaparece, que sea un producto que consumen los hombres en el que las mujeres son las consumidas, no parece ser motivo de crítica política excepto para las feministas, y no para todas. Lo cierto es que el mercado se legitima solo y tiene una capacidad enorme para construir identidades ligadas al consumo que se presentan como neutras.

Y es que la prostitución está relacionada con las identidades patriarcales como veremos en el punto siguiente, pero no se entendería sin las identidades neoliberales; posiblemente, sin la construcción de una identidad neoliberal ligada al consumo, no hubiera sido posible el crecimiento exponencial del uso prostitucional. El núcleo duro de esta ideología sería la identificación del mercado con una realidad natural inapelable (Laval, 2013: p. 12) que es inaccesible a la crítica moral. Si hay alguien que quiere comprar y alguien dispuesto a vender, no hay nada que objetar, ni ninguna ideología tiene nada que decir. No se admite -o se admite cada vez menos y para menos cosas- que haya cuestiones (personas, trabajos, derechos) que puedan quedar fuera de estas reglas y a las que haya que aplicar normas de otro tipo, éticas, por ejemplo, o políticas. Se supone que el mercado se autorregula también

\footnotetext{
${ }^{2}$ La conversión del sexo en mercancía ha sido explicada últimamente por Rosa Cobo (2011 y 2016) y Ana de Miguel (2015)
} 
éticamente. Incluso en ambientes críticos es evidente el crecimiento de un modelo social basado en el mercado como regulador, y al que se accede mediante la libertad individual, libertad que queda plasmada en un contrato. El capitalismo pretende ser también "capitalismo de consentimiento" y requiere de la libertad como condición de posibilidad de la explotación. El instrumento básico que permite conjugar libertad con dominación, que permite otorgar el consentimiento a la propia explotación es el contrato, mediante el cual se aceptan las condiciones estructurales de explotación y de dominación. El contrato, así, lo legitima todo. Y en este hábitat aparece la llamada industria del sexo, una de cuyas ramas es la prostitución. Prostitución y mercado así forman un tándem difícil de combatir porque se refuerzan mutuamente. Si la prostitución sigue teniendo en el imaginario colectivo mucho de sexualidad natural, y llevamos milenios conviviendo con ella, al superponerle ahora la idea de la naturalidad del mercado neoliberal esa idea se refuerza. Muchas personas que se consideran anticapitalistas aceptan con facilidad que el mercado entre en cuestiones que tienen que ver con los cuerpos de las mujeres, seguramente como resultado de siglos de cosificación que han conseguido anular la capacidad crítica en esta cuestión. En general, la sociedad tiende a aceptar como verdaderas aquellas normas que son mayoritariamente aceptadas, como es el caso de la naturalidad del patriarcado.

Cuando hablamos de la industria del sexo hablamos no de cualquier industria, sino de una de las más poderosas del mundo, ligada también a actividades ilegales muy lucrativas y que ha sido capaz de crear, como muy bien explica Rita Segato (2016), estados paralelos con un poder inmenso, con poder incluso para modificar políticas estatales e internacionales. El hecho de que la prostitución haya mutado, desde actividad particular a actividad que se desarrolla en el ámbito industrial y financiero, ha modificado su carácter en cuestiones clave, como por ejemplo el efecto que tiene en la demanda. Esta industria, como cualquier otra, trabaja activamente y tiene estrategias para provocar un aumento constante de la demanda. Eso hace que, por ejemplo, la frase tradicional de que es la demanda la que crea y mantiene la prostitución, siendo cierta requiera ahora una matización. En este momento es posible pensar que es la industria la que hace aumentar la demanda. Estamos hablando de una industria capaz de transformar el mundo en el que vivimos, de crear subjetividades e identidades, con capacidad para incidir en la economía global, en la política de los países, en la cultura, en lo público y en lo privado, y con 
capacidad también para incidir en el orden de género. Hablamos de una industria con una enorme incidencia en el sector del ocio masculino, que ha podido convertir los burdeles en lugares legitimados de socialización masculina, al tiempo que ha conseguido también masculinizar ámbitos laborales que la presencia de mujeres había convertido en espacios más igualitarios y de los que ahora, de nuevo, las mujeres nos vemos expulsadas (Segato 2016). Todos estos sectores trabajan de manera coordinada para aumentar la demanda, lo que hacen mediante legislaciones favorables a sus intereses, publicidad, incidencia cultural y técnicas comerciales muy agresivas. Pocas industrias tienen ese potencial.

Los efectos de la industria sobre la oferta (las mujeres) también existen pero están invisibilizados. En la medida en que la industria presiona para aumentar la demanda, tiene que conseguir aumentar la oferta. Por una parte, la trata de mujeres para prostitución es una consecuencia del aumento de la demanda por encima del número de mujeres dispuestas voluntariamente a ingresar o a permanecer en este mercado. No hay suficientes mujeres que quieran ingresar en la prostitución de manera voluntaria. Al mismo tiempo, esta es una industria que se nutre fundamentalmente de la pobreza femenina: esto quiere decir que la pobreza femenina es condición necesaria para que la industria crezca. En la medida en que hay países cuyo PIB depende de la industria de la prostitución, ¿qué políticas de igualdad van a desarrollar estos países para que sus niñas y jóvenes se formen, trabajen, cobren sueldos dignos si todo eso se traduciría en un descenso de las mujeres que se dedicarían a la prostitución y, así, de sus ingresos? $\mathrm{Y}$ a eso hay que sumarle las presiones de un poderoso lobby que trabaja para que no se adopten medidas que les pudieran ser desfavorables. Su objetivo, aumentar la demanda y conseguir condiciones de explotación mejores para la industria así como legislaciones favorables a su actividad, para lo que ejercen presión sobre los gobiernos e instituciones políticas así como sobre los medios de comunicación con el objetivo de normalizar y banalizar la prostitución, así como crear un estado de opinión favorable a sus intereses. En definitiva, de lo que se trata es de despolitizarla y des-generizarla. Mientras que las feministas hemos conseguido politizar instituciones y prácticas aparentemente mucho más naturales que la prostitución, como son, por ejemplo, la maternidad o el amor romántico, la sexualidad -y la prostitución-, cuya relación con la construcción del patriarcado es inequívoca, va en el sentido opuesto: hacia la despolitización completa. La industria del sexo ha conseguido 
presentar la sexualidad como políticamente neutra, inasequible al análisis político. Y esto es completamente ajeno al feminismo, que hizo del análisis y cuestionamiento de la sexualidad patriarcal uno de sus objetivos teóricos.

\section{LA PROSTITUCIÓN EN LA RE-CONSTRUCCIÓN DE LA SUBJECTIVIDAD MASCULINA HEGEMÓNICA}

Tenemos, pues un modelo económico que construye subjetividades acríticamente favorables al mercado y singularmente favorables a la cosificación de las mujeres. Tenemos una megaindustria transnacional presionando sobre la economía global, el sector del ocio y del entretenimiento, para lo cual necesita que la desigualdad de género se refuerce o, por lo menos, no desaparezca. Lo que tenemos, en definitiva, es el funcionamiento habitual del capitalismo que genera desigualdad al tiempo que refuerza las desigualdades previas.

A esto hay que sumar que nos encontramos en un momento en el que estamos viviendo una profunda reacción patriarcal y antifeminista. Desde mediados de los 80 se puede observar que al igual que muchos otros derechos y muchas otras conquistas sociales, la igualdad entre hombres y mujeres también sufre un retroceso (Cobo 2011, Hernando et. al 2015, Faludi 1991, Walter 2010) No hay avance sin reacción. Vivimos una situación que Lagarde (1990) ha definido como de "brutalización del patriarcado", que se demuestra en una mayor cosificación de las mujeres en todos los ámbitos, mucha más violencia y más cruel, y todo ello cuando el contrato sexual se está debilitando. La cuestión ahora es analizar qué herramientas son las que están posibilitando este retroceso $o$, al menos, reforzando el orden de género que las feministas combatimos. Mi opinión es que la prostitución juega en este momento un papel primordial en esa resistencia patriarcal; un refugio de resistencia individual y colectiva al cambio, un espacio de refuerzo de las subjetividades masculinas fragilizadas, como voy a explicar.

"El orden patriarcal actúa de forma tal que modela nuestra subjetividad desde el inicio de nuestras vidas, dado que es el orden lógico que rige el sistema social. Así pues, la subjetividad de cada uno de nosotros se construye a través de relaciones intersubjetivas entretejidas con sus propios hilos, de forma que nuestra materia prima subjetiva, por así decirlo, es patriarcal" (Hernando 2015: 19). 
El orden social patriarcal está ahí, dentro de cada uno de nosotros y nosotras, es parte de lo que nos construye, nos hace ser las personas que somos. Nadie niega que la variable de la autopercepción del género, la conciencia de ser hombre o mujer, es uno de las más importantes componentes de la identidad. En ese sentido, el patriarcado tiene que ver con las identidades más que cualquier otro sistema de dominación y, sin embargo y aunque parezca mentira, y con notables excepciones, los estudios de las subjetividades no suelen tener en cuenta el género (San Miguel: 153).

En todo caso, hoy nos encontramos en una situación en la que las subjetividades femeninas han cambiado radicalmente en las últimas décadas, no así las masculinas. Es como si las mujeres hubieran hecho una revolución que sólo les atañe a ellas y a sus identidades y sin embargo, pienso que no hay cambio social posible si no se produce también un cambio en las subjetividades masculinas; porque la desigualdad no está ligada sólo a lo material, que es donde el feminismo ha hecho más incidencia, sino que también se clava en el psiquismo. En este sentido, Hernando (2015: 83 y ss.) sostiene que el orden patriarcal no experimentará una quiebra real si sólo lo combatimos con la razón, y no con la emoción. Las razones de la desigualdad ya han sido públicamente impugnadas por el feminismo, pero en cambio los comportamientos, las creencias íntimas, las emociones de la mayoría de los hombres no acaban de cambiar. Incluso es posible que en la medida en que las "razones" igualitarias se impongan, las emociones sean cada vez más desigualitarias. Hannah Arendt explica que cuanto más iguales son las sociedades más desiguales son los individuos, porque necesitan de una ideología cada vez más totalitaria para dominar a otros, a otras en este caso. La ideología que la mayoría de los hombres despliegan para sustentar su lugar en el mundo es cada vez más totalitaria, más agresiva y esto se evidencia en el aumento de la violencia machista, en el aumento de las actitudes de control sobre la pareja por parte de muchos jóvenes o en el uso, cada vez mayor de la prostitución, por ejemplo.

Respecto al género y la identidad, dice San Miguel (163) que el modelo de identidad de género nos deja su impronta en la personalidad y en el psiquismo en tres áreas fundamentales: la regulación emocional, los ideales del yo y el área de los deseos sexuales. Si queremos combatir la desigualdad tendremos que luchar por modificar no sólo lo material sino también aquello a lo que se llega 
con más dificultad pero que impregna nuestros comportamientos y también nuestras percepciones del género, tanto respecto al propio como al otro y en esas tres áreas mencionadas, la prostitución juega un papel.

Hay trabajos suficientes para demostrar que niños y niñas no son criados de igual manera respecto a sus emociones, afectos y deseos sexuales. Desde el comienzo se trata de desarrollar en las niñas la empatía con los estados emocionales de otras personas, mientras que en los niños se desarrolla la agresividad y se busca limitar dicha empatía emocional. En los varones se refuerzan las relaciones instrumentales que se limitan, en cambio, en las niñas. $Y$ todo esto se refleja también en la sexualidad. En las mujeres se hace difícil tener ningún tipo de relación meramente instrumental que no tenga en cuenta los sentimientos de otra persona, mientras que los hombres, por el contrario tienen que aprender a hacerlo. Si queremos combatir la desigualdad tendremos que luchar por modificar no sólo el mundo material que sustenta esta, sino también aquello a lo que se llega con más dificultad, que impregna nuestros comportamientos, emociones, sentimientos, que nos construye y nos hace percibir a los otros de una u otra manera. La prostitución sirve para esto, para enseñar y acostumbrarse a la desigualdad, para materializar la desigualdad en los cuerpos.

Entender la prostitución como elemento importante en la configuración de la identidad masculina, significa, además, darle la vuelta a la explicación tradicional que siempre ha considerado que era la subjetividad femenina la que se construía alrededor de la prostitución: ser o no ser puta. Puta ha sido desde siempre una palabra con un enorme poder para designar (y estigmatizar) a ciertas mujeres, se dedicaran a la prostitución o no. Y si bien puta sigue existiendo como insulto patriarcal, es cada vez menos eficaz en cuanto a su poder para incidir en las subjetividades femeninas. El estigma sigue teniendo eficacia, pero tanto como insulto o como estructurador de la identidad femenina, funciona más en la fantasía masculina que en la realidad. Las mujeres tienen cada vez más capacidad para escapar de dichas heterodesignaciones y autodefinirse. Es decir, una mujer que tiene sexo libremente puede ser tachada de puta por los machistas (y en ocasiones aun por los poderes públicos, judiciales, mediáticos etc.) pero dicha calificación está en decadencia y seguramente ella no se sienta como tal ni sea percibida así por su entorno inmediato. Así pues el peso de la sexualidad se ha aligerado para las mujeres, 
tiene menos significación, juega un papel menor en la configuración de sus identidades: por el contrario, se ha hecho más denso para los hombres, cuya masculinidad social e individual, huérfana de otros apoyos, encuentra en el uso patriarcal de la sexualidad un espacio de refuerzo identitario y de autoconstrucción subjetiva imprescindible. La sexualidad hegemónica masculina ya no puede ser actuada con cualquier mujer, porque ellas se han movido de sitio. Por eso los hombres necesitan de la prostitución para poder recrear una sexualidad (que es más que eso) que no pueden actuar en relaciones no prostitucionales, en las que las mujeres exigen correspondencia e igualdad; cuestiones estas que hasta hace poco tiempo ninguna mujer exigía.

En cierto sentido, la prostitución funciona a modo de estabilizador de género que (re)construye constantemente esos tres aspectos que mencionaba San Miguel. Joan Scott, en un texto clásico, explica que la idea de género se usa para delimitar construcciones culturales basadas en la diferenciación sexual (1986). Para ella, la diferenciación sexual es todo un sistema que abarca prácticamente todos los aspectos de la vida humana, desde la propia subjetividad, hasta los comportamientos sociales de hombres y mujeres, pero también a los comportamientos sexuales que, a su vez, son uno de los pilares de las identidades generizadas. Así, la idea de género, las identidades masculinas o femeninas no responden a procesos individuales que se puedan desarrollar aisladamente en el plano psicológico, sino que se llega a ser hombre o mujer a partir del despliegue de una serie de roles y comportamientos que abarcan todo lo que entendemos por masculinidad y feminidad. Scott (1986, p. 1068) entiende el género como una construcción hecha con cuatro materiales: símbolos culturalmente disponibles, conceptos normativos que fijan las interpretaciones de esos símbolos, instituciones y organizaciones políticas y sociales, e identidad subjetiva. La prostitución es una institución tan vinculada al patriarcado que comparte estos cuatro materiales. No obstante, aquí voy a referirme al último de ellos, a la identidad subjetiva generizada. Y para explicar de qué manera la prostitución interpela/refuerza la subjetividad masculina hay que tener en cuenta dos cuestiones clave que están presionando sobre dicha subjetividad. Por una parte, de nuevo, el neoliberalismo, no en el sentido ahora que hemos explicado antes, como constructor de una determinada razón o inteligibilidad que mercantiliza todo lo humano, sino en el sentido de constructor de desigualdad y pobreza $\mathrm{y}$, a su vez, la relación de esta desigualdad con la subjetividad masculina por una parte, y por la otra, con el feminismo. 
En relación con lo primero, vemos que desde los años 80, cuando el capitalismo se convierte en el neoliberalismo global que conocemos y que ha precarizado al extremo la vida de millones de seres humanos, algunas instituciones y prácticas patriarcales, la prostitución entre ellas, adquieren más importancia ahora que nunca en tanto que funcionan como una espita que permite relajar el conflicto social. El objetivo es que una vez que a los hombres se les ha quitado todo, tengan al menos el cuerpo de las mujeres como una forma de recuperar algo del poder perdido (Federici, 2016). Por una parte el neoliberalismo global ha sumido en la pobreza a millones de personas, ha cambiado los modelos económicos tradicionales, las políticas de subsistencia de muchas comunidades, ha fragilizado extraordinariamente las vidas de las personas ${ }^{3}$. Esta situación económica ha venido a cambiar fundamentalmente la estructura tradicional familiar de hombre sustentador que ya no puede, debido al desempleo, la precariedad y los magros salarios, ser el único proveedor familiar. Y esta expropiación de ese rol de proveedor es más importante de lo que parece. Como bien explica Fraser (2015: 55-63) existe un sentido muy profundo en el que la identidad masculina está ligada en estas sociedades al rol de proveedor económico de la familia. La masculinidad en gran parte del mundo consiste en salir de casa y volver con un salario que provee a los que dependen de uno; existe una relación interna entre ser hombre y ser proveedor, lo que explica por qué en las sociedades capitalistas el desempleo puede ser psicológica, así como económicamente, tan devastador para los hombres. Por su parte, el trabajo femenino, más barato, más precario, más intercambiable, es ahora, en muchas ocasiones, preferido al trabajo masculino. Las migraciones femeninas en busca de empleo han llevado a que millones de mujeres hayan desplazado a los hombres de sus lugares de sustentadores principales. En cierto sentido, el neoliberalismo, Segato lo explica muy bien, ha situado a los hombres en una posición en la que antes se encontraban las mujeres, los ha feminizado, emasculado. Ese cambio radical, sin que se haya producido al mismo tiempo un cambio de mentalidades, sólo podría provocar una crisis en esas subjetividades masculinas, con sus correspondientes estallidos de furia. Fraser (2015) explica que hay conflictos propios del capitalismo tardío que responden más a tendencias en la reproducción simbólica que en la material, y la crisis de identidad del género masculino sería una de esas tendencias. Esa crisis de identidad, producto de la guerra del capitalismo contra las personas, se produce porque los hombres no han cambiado esencialmente los elementos que

\footnotetext{
${ }^{3}$ En realidad, las mujeres siempre hemos estado en esa posición. Dicha posición sólo se considera una crisis cuando afecta a los hombres.
} 
componen unas identidades de género que ahora son acosadas por el sistema económico y por el feminismo; por tanto, para sanarse lo que buscan es una reconstrucción permanente de aquellas, y eso lo hacen mediante las mujeres. Las mujeres son el medio para reconstruir sus identidades fragilizadas.

Además, esta crisis de las masculinidades tradicionales no se debe sólo a las políticas neoliberales sino a la combinación de estas con los éxitos y avances del feminismo, que ha venido a cambiarlo todo: los roles sociales, subjetivos, familiares, laborales etc. Entre una y otra presión, las masculinidades tradicionales se han ido quedando sin sitio: el hombre ya no manda en casa, ni sobre su mujer, ni sobre sus hijos. No ocupa como indudable superior, el espacio laboral, donde ahora puede tener una jefa, donde encuentra límites al acoso sexual, a los chistes machistas...; la calle tampoco es ya su espacio en exclusiva. Familia, empleo, espacio público, ya no son lugares de dominio masculino. Cambian los roles que se pueden manifestar en público, pero no los que se manifiestan en privado, lo que da cuenta de la resistencia de los hombres a asumir el nuevo escenario. El estallido patriarcal se muestra en el aumento y la crueldad de la violencia contra las mujeres por una parte y por la otra en el aumento del uso de la prostitución como alivio patriarcal, como espacio de reconfiguración de los roles sexuales tradicionales y de las masculinidades hegemónicas. La prostitución, así, tiene una importancia fundamental en la regulación emocional patriarcal, porque ayuda a reconstruir los ideales del yo ligados a la masculinidad y a cumplir con los deseos sexualmente culturalmente asignados a aquella. Quien no tiene nada tiene al menos el cuerpo de las mujeres que le confirma que es alguien. La sexualidad vertida sobre ese cuerpo, expresa el acto domesticador, apropiador cuando insemina (aunque sea simbólicamente) el territorio-cuerpo de la mujer (Segato, 2016: 35).

Veamos ahora qué rasgos caracterizan a esa subjetividad masculina hegemónica y por qué la prostitución la refuerza y reconstruye. Según Bonino entre otros rasgos podríamos señalar un yo centrado en sí mismo que prioriza los deseos propios, dominio y control de sí y de los demás, escasa empatía, disociación razón/emoción, renuncia a motivaciones de apego, un deseo sexual legitimado y vivido como algo autónomo y una creencia que considera a los hombres superiores a las mujeres (Bonino 2000 cit., en Herce: 130) Por supuesto que los polos puros no existen y que todas las identidades son una mezcla de estos rasgos en mayor o menor medida junto con otros como la familia, la experiencia 
personal, los mandatos culturales, de clase etc. pero es evidente que los elementos que construyen las subjetividades masculina y femenina siguen siendo muy diferentes. Lo importante es que estos rasgos han sido criticados y cuestionados por las mujeres, que demandan ahora relaciones igualitarias basadas en la empatía, el apego, la entrega emocional etc., por lo que ya no es fácil ejercer esa manera de ser hombre. El espacio en el que sí pueden ejercerse es en el espacio prostitucional.

Tenemos que recordar que cuando hablamos de prostitución no hablamos de una práctica exclusivamente sexual, que venda orgasmos, ya que los orgasmos rápidos son algo que se puede obtener de manera fácil y gratuita, no lo olvidemos. Hablamos de una institución con su propia genealogía, una institución cuyo significado trasciende a las prácticas individuales y que ofrece, por tanto, un valor añadido a dichas prácticas; podríamos hablar incluso de "plusvalía de género". El uso de la prostitución aparece así como un refugio, un espacio en el que los hombres pueden ser los hombres que quieren, un espacio baluarte para poder encarnar la desigualdad desde una posición de dominio incontestado. Los hombres cuya masculinidad es frágil, y por lo tanto también lo es su autoestima, viven la igualdad como una amenaza porque contradice su creencia interiorizada en su propia superioridad ${ }^{4}$. Estos hombres llegan a percibir la realidad de un modo distorsionado en el cual su masculinidad siempre está en peligro y por eso necesitan reafirmarla constantemente, ante sí mismos y ante los demás (Herce: 131 y ss.).

Como sabemos, ese proceso de obtención de la masculinidad obedece a procesos diferentes a los que se ponen en marcha para la producción de la feminidad. La masculinidad hay que obtenerla, ganarla y mantenerla, es decir, tiene que ser reconfirmada todo el tiempo. Y esa confirmación sólo la pueden ofrecer las mujeres. Son las mujeres las que les confirman a los hombres que lo son. Eso hace que los hombres estén en una situación de cierta dependencia respecto a ellas, y más aún en este periodo en el que lo que los hombres necesitan ser y lo que las mujeres quieren que los hombres sean, se ha producido una disonancia. Por eso la prostitución es necesaria, porque en la prostitución los hombres ven confirmada su masculinidad, fuente de su autoestima básica. Las prostitutas son objetos de mediación y la prostitución es

\footnotetext{
${ }^{4}$ Según un estudio de la Comunidad de Madrid (Aguirre et al, 2012: 73 en Herce 131) los hombres viven la lucha de las mujeres por la igualdad casi como maltrato psicológico, como una invasión, un intento de dominación.
} 
una performance de poder patriarcal que les permite rehacer su virilidad y revalorizar su autoimagen (Lagarde, 1990: 579). En realidad, la prostitución es una performance del patriarcado en su conjunto (y también del neoliberalismo), un espacio privilegiado en el que poner en funcionamiento el pacto patriarcal; el lugar en el que ellos pueden consumir mujeres y poner en funcionamiento determinados valores relacionados con el mandato neoliberal de buscar a toda costa la satisfacción del propio deseo, sin ningún tipo de consideración ética, al mismo tiempo que permite actuar el tradicional rol de género masculino $y$ hacer realidad el intercambio simbólico de mujeres. Es ahí, hoy día, donde las mujeres son verdaderamente intercambiables y públicas, cuando eso ya no ocurre en otros espacios.

Además, la prostitución tiene importancia como lugar desde el que poder actuar esa sexualidad desconectada que es también un rasgo de la masculinidad hegemónica. Pero es también un lugar de disciplinamiento de la propia sexualidad, del funcionamiento de los genitales masculinos en realidad. El uso que los hombres hacen del funcionamiento de los genitales masculinos se ajusta lo que Bourdieu (2000:38) ha llamado "somatización de las relaciones sociales de dominación". Este autor plantea que en las relaciones de dominación es necesario un emblema o un estigma cuya eficacia simbólica radica en que se trate de una característica corporal; dicha marca corporal es arbitraria pero nuestra cultura ha determinado que los genitales masculinos sean esa marca, para lo cual es necesario que se pongan erectos ante cualquier estímulo sexual, así como que estén siempre dispuestos a penetrar; y así, no hay sexo sin penetración y en esa penetración no se juega tanto el goce como la propia masculinidad. Ese uso de los genitales masculinos, a modo de emblema de la masculinidad, construye el binomio masculinidad/feminidad en términos jerárquicos de manera incuestionable $\mathrm{o}$, al menos, desde el punto de vista masculino así lo sienten los hombres. Ser superior es consustancial a ser hombre. En una sociedad en la que las mujeres ya no son ni se sienten inferiores, la prostitución es la institución en la que los hombres pueden ejercer esa masculinidad que ya no encuentra otro espacio.

A pesar de los avances de las mujeres y de los cambios, la sociedad continua dando carta de naturaleza a un modelo naturalizado de deseo sexual masculino como una necesidad natural e irreprimible de penetración que debe expresarse mediante el coito heterosexual y que satisface más cuanto mayor es la 
frecuencia con la que se ejercita y la variedad de mujeres con las que se pone en práctica (Gimeno 2012:74) Todo ello favorece la identificación que se hace de este modelo de sexualidad con el "sexo" y prepara para convertir esta necesidad masculina en un derecho de los hombres a disfrutar o usar de las mujeres (Herce: 135) Esto es lo que se transmite desde el orden social: que para ser un verdadero hombre, el órgano sexual debe estar muy activo, se le debe procurar todo el placer que se pueda y esto, además, tiene que gustarles a las mujeres. Para esto la prostitución es insustituible, porque las mujeres han aprendido a decir no y a expresar sus propios deseos. Cierto que el modelo de masculinidad dominante está presente en todas las instituciones sociales, pero la prostitución lo hace físicamente real, lo pone al alcance material de todos los hombres.

La escuela de la sexualidad masculina es una escuela de dominación masculina como tan bien explicó Bourdieu. Cuando una persona experimenta deseo, dicho deseo puede activar o no el deseo del otro. Sin embargo, en el modelo hegemónico patriarcal, cuando el hombre experimenta deseo, la mujer experimenta deseo de ser deseada. El lugar del sujeto es la posición masculina y el lugar femenino es el lugar del objeto sexual, un mero medio para cumplir deseos masculinos. En la prostitución se asegura que no haya imprevistos para los hombres (la variedad y multitud de mujeres asegura encontrar la que diga que sí a cualquier deseo) En cambio, no existe una representación real del deseo femenino. Lo que aprenden ellos acerca de la sexualidad femenina en la prostitución (y en la pornografía) es que las mujeres desean lo que ellos desean, que son cuerpos penetrables y que están ahí para su placer. La prostitución sirve para ahorrarles a los hombres el riesgo de no ser deseados y es en ese sentido en el que podemos hablar de "plusvalía de género", la prostitución les ofrece la posibilidad de una performance de género de la que siempre salen triunfantes.

Hay muchos relatos en la literatura acerca de primeras experiencias sexuales masculinas con prostitutas y la mayoría de ellas no son agradables ni placenteras, sino traumáticas. Lo que se cuenta en dichas experiencias es que el chico lo que en realidad aprende en sus visitas a los burdeles es a disciplinar el asco, el miedo, la indiferencia y a identificarlo con un sentimiento de valía, así como a tener una erección, que es lo que demuestra que es un hombre de verdad. Un chico será un hombre si es capaz de tener muchas relaciones 
sexuales sin importar su propia apetencia y mucho menos la de su compañera, que se convierte de manera inevitable en un medio en el camino de la exaltación de la masculinidad. Finalmente, una sexualidad así cosificada sólo puede ejercitarse gracias a la prostitución porque pocos hombres pueden tener todo el sexo que su masculinidad les exige. La prostitución permite tener todo el sexo que la masculinidad necesite sin que el deseo de la otra persona sea una variable a tener en cuenta.

No obstante, el sentimiento de superioridad o masculinidad propuesto en este modelo está permanentemente amenazado. Por una parte, para que sea completo, ella no puede ser una persona autónoma, porque tiene que mostrar admiración, confirmarle que es más hombre que nadie, que la tiene más grande, que es muy bueno follando. Esa participación de ella es imprescindible. Antiguamente, cuando la prostitución no estaba para reafirmar la masculinidad, puteros y prostitutas tenían, o podían tener, relaciones más cercanas, humanas al menos. Ellos podían permitirse sentir por ellas cierto agradecimiento, incluso cariño (un cariño devaluado, ciertamente), las relaciones largas eran frecuentes. En cierto sentido ellas no eran tanto mujeres de usar y tirar como mujeres jerárquicamente inferiores a las demás mujeres y todas inferiores a ellos. Ahora, muchos puteros sienten odio hacia ellas. Sospechan que les mienten y por eso, a pesar de que ellas siempre les dicen lo que quieren oír, las odian porque dependen más que nunca de la valoración de personas que han denigrado previamente hasta el extremo. El odio de los puteros por las putas es mayor que nunca porque no deja de ser el odio que sienten por todas las mujeres y no pueden expresar en su vida cotidiana. De este odio queda constancia en las redes y en los foros de puteros.

\subsection{Escuela de desigualdad social}

¿Es posible pensar que no tiene ninguna consecuencia en la construcción de la desigualdad sexual que todo niño, joven, hombre, desde que tiene uso de razón, en cualquier lugar del mundo, en cualquier ciudad, de cualquier clase social sepa que por el mero hecho de ser varón puede acceder al cuerpo de una mujer por un dinero al alcance de cualquier bolsillo? Es decir, que todo niño/hombre del mundo sabe que follar a una mujer de cualquier manera que a él le apetezca, no es sólo su deseo, sino que es su derecho. Lo que antes era el derecho a violar en los patriarcados de coerción, ha sido sustituido en los patriarcados de consentimiento por el derecho a comprar. El niño aprende 
enseguida que satisfacer su deseo es un derecho y aprende, al mismo tiempo, que el placer de ellas no importa en absoluto o, peor aún, que el placer de ellas es satisfacerle a él. Y siguiendo con la pregunta del principio, este uso de las mujeres ¿no tiene consecuencias en la manera en que construyen sus emociones sexuales, sus mapas afectivos, sus sentimientos, sus imaginarios, sus deseos?

Porque las niñas no crecen así. Las niñas no están en esa posición, sino en la contraria. Ellas saben, muy pronto que son la materia prima con la que se construye ese espacio físico y simbólico, hecho de deseos, emociones, normas, dispositivos, poder...que es el espacio de la prostitución. Ella aprenderá que su placer no importa, que su misión es darle placer a ellos. Aprenderá que mientras su chico puede ir a un prostíbulo, ella no puede ir. Aprenderá que lo que el desee sexualmente tiene derecho a conseguirlo ya que la sociedad parece organizada para que tenga siempre mujeres a su disposición. Él tiene millones de vaginas, anos y bocas a su servicio. ¿Es posible inculcar igualdad a niños y niñas en esa situación? ¿Decirles que son iguales? El aprenderá, además, como distanciarse emocionalmente de las mujeres ya que todo el rato se le presentan, desde la publicidad a la pornografía y luego en el prostíbulo, como anos, bocas o vaginas por penetrar. Ellas ahí siempre sonríen y parecen desear eso. Es todo un aprendizaje emocional. El mandato social es muy potente para ellos y ellas, pero es divergente. Ellos tienen que "narcisizar" su actividad sexual mientras que ellas tienen que narcisizar su cuerpo (Walter, N. 2010 cit. en Herce: 139) A ellos les gusta su propio pene, a ellas les gusta resultar atrayentes para el pene. La paradoja de la heterosexualidad, como señaló muy agudamente Josep Vicent Marqués (1981:86 Marqués, J, V cit. en Aguilar: 48) es que a los hombres, en realidad, no les gustan las mujeres como personas, sólo se gustan a sí mismos.

Este es el material con el que niños y niñas tienen que construir sus subjetividades. Hay otros muchos materiales genéricos, desde luego, pero pocos son tan universales, tan constantes $y$, sobre todo, tan imposibles de intercambiar. Aquí no es posible poner a las mujeres en el lugar de los hombres. No es posible que las niñas crezcan pensando que tendrán acceso a cuerpos masculinos (sin que el deseo de ellos juegue un papel), ni ellos crecerán con el miedo a ser uno de esos cuerpos penetrables a cambio de dinero. Las defensoras de la inocuidad de la prostitución dirán que no es más que un servicio como cualquier otro y que los genitales no tienen tanta importancia pero para ellos sí que la tiene; es obvio que la tiene o no existiría todo un sistema montando para 
que sus genitales obtengan siempre satisfacción. En realidad, lo que no tiene importancia son los cuerpos femeninos y los sentimientos de las mujeres porque son una mercancía barata que se ofrece en un mercado mundial que, previamente, ha creado las condiciones para que las mujeres entren en el mismo. ¿Qué algunas mujeres consiguen mejorar su situación ejerciendo la prostitución? Claro, porque previamente han sido despojadas de todo (de los recursos materiales y simbólicos) para que la prostitución sea su única opción. $\mathrm{Y}$ aunque algunas mejoren su situación personal, la desigualdad se fortalece cuando aceptamos como normal la desigualdad estructural de partida, así como la forma en que ésta se refuerza en cada acto prostitucional.

La prostitución está hecha de desigualdad. Para existir necesita de la desigualdad económica y cultural o millones de mujeres no se dedicarían a ella. Pero, además, necesita y refuerza la desigualdad de género, la ideología de la desigualdad sexual que es, a su vez, un enorme refuerzo personal en momentos en los que las feministas y la igualdad formal están quebrando certezas profundamente arraigadas. El neoliberalismo hace lo propio de otra manera. Hernando (2016: 119) asegura que para la igualdad es imprescindible que los hombres refuercen su identidad relacional, es decir, la empatía por el otro/la otra; que se vean en lo que llamamos cuidado, y así, les sea difícil hacer sufrir a otra persona, violentar su cuerpo, despreciar su deseo. En definitiva, para que la igualdad sea un hecho es necesario que los hombres sean capaces de supeditar siempre el propio deseo al deseo ajeno, vivirlo en igualdad. Y la prostitución está ahí, justamente, para que esto no se produzca.

\section{BIBLIOGRAFÍA}

Aguirre, R.; Cruz, J.L.; Garabato, S.; Lasheras, L; Pires, M. y Ramasco, M. (dir.) (2010). Salud, violencia de género e inmigración en la Comunidad de Madrid. Madrid: Documentos Técnicos de Salud Pública, Madrid, Subdirección de Promoción de la Salud y Prevención/ Dirección General de Atención Primaria.

Aguilar, P. (2015). La ficción audiovisual como instrumento de educación sentimental en la Modernidad. En A. Hernando (ed.), Mujeres, hombres, poder. Subjetividades en conflicto (pp. 25-53). Madrid: Traficantes de Sueños.

Amorós, C. (2005). La gran diferencia y sus pequeñas consecuencias... para las luchas de las mujeres. Madrid: Cátedra. 
Arendt, H. (2016). Los orígenes del totalitarismo. Madrid: Alianza Editorial.

Bonino, L. (2000). Varones, género y salud mental.: deconstruyendo la normalidad masculina. En M. Segarra y A. Caribí (eds.) Nuevas masculinidades (pp. 41-52). Barcelona: Icaria.

Bourdieu, P. (2010). La dominación masculina. Barcelona: Anagrama.

Cobo, R. (2011). Hacia una nueva política sexual. Las mujeres ante la reacción patriarcal. Madrid: Libros de la Catarata.

Cobo, R. (2016). La prostitución en el corazón del capitalismo. Madrid: Libros de la Catarata.

Connell, R.W. (2003). Masculinidades. México: PUEG.

Fraser, N. (2015). Fortunas del feminismo. Madrid: Traficantes de sueños.

Gimeno, B. (2012). La prostitución. Barcelona: Bellaterra.

Herce, J. (2015). Las relaciones entre hombres y mujeres hoy: Los nuevos desencuentros. En A. Hernando (ed.) Mujeres, hombres, poder. Subjetividades en conflicto (pp. 125-150). Madrid: Traficantes de sueños.

Hernando, A. (2015). Identidad relacional y orden patriarcal. En A. Hernando (ed.). Mujeres, hombres, poder. Subjetividades en conflicto (pp. 83-120). Madrid: Traficantes de sueños.

Kinsey et al. (1948). Sexual Behavior in the Human Male. Philadelfia: Sounders Company.

Lagarde, M. (1990). Los cautiverios de las mujeres. Madrid: Horas y Horas.

Laval, C. (2013). La nueva razón del mundo. Barcelona: Gedisa.

Miguel, A. (2015). Neoliberalismo Sexual. Valencia: Cátedra.

Marqués, JV. (2001). ¿Qué hace el poder en tu cama?. Barcelona: Icaria.

Puleo, A. H. (1995). Patriarcado. En C. Amorós (coord.): 10 palabras clave sobre mujer. Navarra: Verbo Divino.

San Miguel, M. (2015). Efectos en las subjetividades contemporáneas de la desigualdad y de las relaciones de poder entre los modelos de masculinidad y feminidad. En A. Hernando (ed.). Mujeres, hombres, poder. Subjetividades en conflicto (pp. 151-174). Madrid: Traficantes de sueños.

Scott, J. (1986). Gender: A Useful Category of Historical Analysis. The American History Review, 9 (51), 1053-1075.

Segato, R. (2016). La guerra contra las mujeres. Madrid: Traficantes de sueños.

Tornay, M.C. (2016): Entrevista a Silvia Federici, Revista Pueblos. Recuperado de: http:// www.revistapueblos.org/?p=21144

Walter, N. (2010). Muñecas vivientes. El regreso del sexismo. Madrid: Turner Noema. 